\author{
Izabel Solyszko Gomes \\ Universidad Externado de Colombia, Bogotá, Colombia
}

\title{
Feminicídios: um longo debate
}

\begin{abstract}
Resumo: O problema da mortalidade violenta de mulheres foi denunciado pelos movimentos feministas há mais de trinta anos e, portanto, há algum tempo já se sabe que a violência de gênero contra as mulheres tem uma expressão letal. Entretanto, o reconhecimento dessas mortes como um "feminicídio" é um processo mais recente. O objetivo deste artigo é apresentar um panorama da produção epistemológica feminista latino-americana que reconhece três ênfases na análise, compreensão e resposta para os feminicídios: um conjunto de diversas mortes violentas em razão do gênero, os assassinatos cujas características conformam feminicídios e, dentre estes, a reivindicação de uma resposta penal específica ao fenômeno. O caminho deste debate é longo, mas de extrema necessidade frente à realidade de matança das mulheres.
\end{abstract}

Palavras-chave: feminicídios; violência de gênero; epistemologia feminista

\section{Introdução}

O feminicídio é a morte violenta de uma mulher pela sua condição de gênero-esta é sua definição mais abrangente. Discutir sobre as mortes de mulheres é tarefa de ordem teórico-prática bastante complexa, na medida em que são tantas as singularidades frente à letalidade da violência de gênero, que o terreno de análise torna-se instável, mas imprescindivelmente necessário percorrer.

Os movimentos de mulheres e feministas foram os principais responsáveis por denunciar a letalidade da violência praticada contra as mulheres, expressa e nomeada nos feminicídios. O debate, que assim nomeava o fenômeno, começou nos anos 90 , nos Estados Unidos, e foi apropriado por mexicanas, para denunciar a existência de feminicídios em Ciudad Juárez - cidade fronteiriça ao norte do país. Posteriormente, o diálogo teórico e as denúncias alcançaram vários países da América Latina. É importante reconhecer que a denúncia dos feminicídios e o desenvolvimento da compreensão sobre eles se deu no conjunto dos movimentos de mulheres e feministas e seu aperfeiçoamento teórico-conceitual se forjou no âmbito da epistemologia feminista.

Para compreender a ocorrência dos feminicídios faz-se necessário, reconhecer as novas formas de atualização do patriarcado e a existência de uma necropolítica que

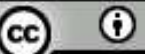

Esta obra está sob licença Creative Commons. 
opera através de um necropoder. No interior da compreensão teórica dos feminicídios, como produto de investigação doutoral, se reconhecem três vertentes que ocorrem em diferentes contextos e requerem o devido enfrentamento. Para isso, se realizou uma revisão bibliográfica das publicações latino-americanas, onde se verificou que o conteúdo das mesmas versava, ora sobre os assassinatos das mulheres em razão da condição de gênero, ora denunciando as numerosas formas de mortes violentas de mulheres (estupros, mortalidade materna e outras que não necessariamente eram os assassinatos). Em outros casos, o debate centrava na necessidade ou não, de criação de um tipo penal para os assassinatos de mulheres, por motivos de gênero (Izabel GOMES, 2013).

Dessa maneira, a partir de minuciosa análise dessa ampla produção acerca dos feminicídios, se reconhece as três vertentes e se reforça a importância de identificá-las e compreendê-las, sob pena de confundir o debate e o enfrentamento do fenômeno.

Uma primeira vertente reconhece o fenômeno a partir de todas as mortes violentas de mulheres, cuja ocorrência tem como causa central, a discriminação e as desigualdades de gênero. Esta é a vertente "genérica" porque concebe o feminicídio a partir de um conjunto de mortes tais como o assassinato de mulheres, as mortes decorrentes de aborto inseguro, as decorrentes de mortalidade materna, aquelas causadas pela prática da mutilação genital e até mesmo casos de suicídios, que se dão em contextos de extrema opressão.

Uma segunda vertente reconhece o fenômeno a partir dos assassinatos de mulheres. Aqui, são os assassinatos, que se tornam objeto de análise e reflexão para compreender um conjunto de singularidades que os caracterizam. Chamamos a esta vertente, "específica" porque se restringe a tais crimes. Esta é a vertente mais difundida, e por isso, quando se fala de feminicídios, geralmente se está referindo ao problema dos assassinatos de mulheres.

A terceira vertente, identificada no debate, compreende o tema da judicialização. Aqui o foco está no diálogo entre o feminismo e o direito penal, para analisar e avaliar a necessidade de um tratamento penal adequado para os assassinatos de mulheres entendidos como feminicídios, verificando a insuficiência do tipo penal 'homicídio'. Chamase a vertente "judicializadora", já que pressupõe todo o debate acerca da judicialização da violência de gênero.

O objetivo deste artigo é, portanto, problematizar o caminho construído no interior da epistemologia feminista latino-americana acerca dos feminicídios. Um longo e penoso caminho, contudo fundamental, a ser percorrido.

\section{A epistemologia feminista e o reconhecimento da existência dos feminicídios como um fenômeno social}

Os feminismos e sua epistemologia feminista são chaves analíticas para começar este caminho. Aqui se entende o feminismo em sua pluralidade, expressas em um conjunto de práticas desenvolvidas pelas mulheres, com objetivo de enfrentar a realidade que as exclui.

No feminismo, a mulher é o sujeito das suas construções, ou seja, é fundante de sua história. A partir da experiência, confluem ideias e auto reconhecimento. A radicalidade está em privilegiar sujeitos historicamente oprimidos e discriminados ao colocá-los como protagonistas do real, portanto, é um movimento com vistas à liberação e à emancipação. No entanto, a condição de mulher não é entendida como uma essência fixa, mas como um conjunto plural. Para o feminismo, o sujeito mulher:

Não é uma essência monolítica definida de uma vez e para sempre, mas é o lugar de um conjunto de experiências múltiplas e complexas e potencialmente contraditórias, 
definido por variáveis que se sobrepõe tais como as de classe, raça, idade, estilo de vida, orientação sexual e outras. A pessoa fala como mulher com o propósito de dar maior força às mulheres, de ativar mudanças na sua condição simbólica. Esta é uma posição radicalmente anti-essencialista (Francesca GARGALLO, 2006, p.71).

A epistemologia feminista, num sentido restrito, reflete a aproximação das mulheres com um campo do saber - o científico - a partir da decisão de questionar padrões científicos, que historicamente as excluíram da sua produção de conhecimento. Todavia, num sentido mais amplo, esta epistemologia pode ser compreendida como todo o conhecimento produzido pelas mulheres, acerca da leitura e da experiência de mundo. Neste sentido, a experiência é chave para contrapor-se às noções naturalizadoras das práticas sociais (Sondra FARGANIS, 1997).

O pensamento crítico feminista surgiu como novidade no campo acadêmico e impõe-se como uma tendência teórica inovadora e de forte potencial crítico e político, o qual, a partir da década de 1970, evidencia um debate sobre a questão da Ciência, cujas especialistas passaram a se perguntar: em que medida a Ciência discrimina a presença das mulheres? (Lourdes BANDEIRA, 2008, p.218).

Neste sentido, é com base nesta episteme que se torna possível identificar, como a violência de gênero se expressa fatalmente na vida e no corpo das mulheres e quais são as mediações e características desse fenômeno.

É fundamental identificar as mortes de mulheres como feminicídio', em especial determinados assassinatos, a fim de visibilizar a letalidade e a não acidentalidade da violência de gênero. Esta "visibilização" esperada na identificação do fenômeno como feminicídio não se trata apenas de trazer à tona o que estava oculto, mas de politizar algo já naturalizado, ou que não foi observado e reconhecido em seu contexto de produção, qual seja, o patriarcal e necropolítico. (Ana María de la Escalera MARTíNEZ, 2010).

Reconhecer a existência dos feminicídios e identificá-los dentre as mortes de mulheres é tarefa fundamental, no marco de um processo em defesa dos direitos humanos, porque apropriar-se do vocabulário "feminicídio" implica em apreender um conjunto de concepções teórico-políticas que localizam a violência de gênero, suas características e seu contexto de produção.

Vale ressaltar que, desde os anos 70 , os movimentos de mulheres denunciaram os assassinatos de mulheres como produtos do patriarcado e, com base numa epistemologia feminista, se elaborou, pesquisou e fundamentou sobre esse fenômeno social (Mariza CORRÊA, 1981; 1983; Guita Guin DEBERT; Daniele. ARDAILLON, 1987; Myrian JIMENO, 2002). Entretanto, apenas nos anos 2000, a letalidade da violência de gênero contra as mulheres passou a ser nomeado enfaticamente como feminicídio na América Latina, em um processo bastante singular em cada país.

Ainda que o termo tenha sido usado por Russell em 1976 nos Estados Unidos, na América Latina, foram com as pesquisas na Costa Rica e com a realidade de Ciudad

'É comum a questão: "femicídio" ou "feminicídio"? O termo foi difundido em inglês, femicide na década de 90 para designar assassinatos misóginos de mulheres (Diana RUSSELL , Jill RADFORD, 2006). Algumas feministas latino-americanas como Ana Carcedo e Montsserrat Sagot $(2000,2010)$ traduziram informalmente o conceito para o espanhol como "femicidio" e Suely Almeida (1998), no Brasil, fez o mesmo para o português. Já Marcela Lagarde (2006), ao traduzir oficialmente para o espanhol os textos de Russel e Radford apresentou o termo como "feminicídio", entendendo-o como mais coerente e acrescentou também que, para compreender o fenômeno no contexto latino americano, se fazia necessário adicionar a noção de impunidade. Logo, a dubiedade na tradução dos termos, fez com que "femicidio" e "feminicídio" fossem difundidos por toda a América Latina para abordar basicamente o mesmo problema.. No caso do Brasil, em março de 2015 , foi sancionada a Lei 13.104/2015 que alterou o código penal e criou a qualificadora "feminicídio" o que pode ajudar a difusão deste termo (e não femicidio como alcunhou inicialmente Suely Almeida). 
Juárez, no México, que o conceito foi mais desenvolvido (Julia Estela Fragoso MONÁRREZ, 2000; CARCEDO, SAGOT, 2000; RUSSELL, RADFORD, 2006). Gradativamente, femicidio/ feminicídio foi sendo utilizado em diversos países latino-americanos, sendo o Brasil um dos últimos a incorporá-lo. Isto ocorreu porque, de um lado, foi difundida a ideia de feminicídios para assassinatos de mulheres ocorridos com características específicas, vivenciados especialmente em zonas fronteiriças do México e centro-americanas. De outro lado, porque se debatia sobre a característica genérica do conceito e da alusão direta que se fazia do debate sobre a tipificação do fenômeno - vide, por exemplo, as críticas de Wania Pasinato (2011).

É neste sentido que se torna fundamental reconhecer as três vertentes do debate teórico sobre o feminicídio e o conjunto de autoras que tecem esse diálogo. Justamente porque cada vertente enfatiza contextos diferentes da ocorrência do fenômeno e requer para ele, enfrentamento devido. O conjunto da bibliografia produzida no interior da epistemologia feminista revela três maneiras de abordar o problema dos feminicídios, e seu reconhecimento possibilita chaves analíticas para o debate. Ao mesclar distintas vertentes sem seu devido reconhecimento, multiplicam-se os equívocos, dificultando, por conseguinte, o que se pretende examinar. Muito mais que disputas conceituais, o que existem aqui são compreensões e ênfases distintas acerca de um fenômeno social, cujas raízes encontram sustento e possibilidade de reprodução numa sociedade patriarcal que opera por meio da necropolítica (GOMES, 2014).

\section{Estruturas e mediações possíveis para pensar a produção dos feminicídios}

O feminicídio é a morte violenta de uma mulher. Dizer feminicídio implica revelar a não acidentalidade e a não eventualidade nesta violência letal, para compreender os fatos como um fenômeno inscrito em determinada estrutura social, extremamente desigual, que possibilita sua ocorrência. É importante problematizar a existência dos feminicídios a partir da compreensão dos pilares que o constituem, quais sejam: o patriarcado, solo fértil para proliferar a expressão letal da violência de gênero e seu corolário, um Estado necropolítico, que produz e sustenta abissais desigualdades sociais e múltiplas formas de violências.

O reconhecimento de uma sociedade patriarcal é fundamental, para entender o fenômeno dos feminicídios e de todas as formas de violência e discriminação sofridas pelas mulheres, mas também, para entender determinada forma de violação aos direitos humanos de todas as pessoas que fogem de um padrão hegemônico, em especial, de ser mulher e de ser homem.

Neste sentido, é de suma importância falar em patriarcado e refletir sobre sua atualidade e vigor. O patriarcado é uma estrutura social e política que distingue homens e mulheres e valora-os mais que elas (Kate MILLET, 1970). Trata-se de um "regime de dominaçãoexploração das mulheres pelos homens" (Helleieth SAFFIOTI, 2004, p.44).

A compreensão do patriarcado enquanto elemento estrutural da realidade, permite entender que não se trata de uma prática masculina, mas de uma estrutura hierárquica, que fomenta práticas "independentemente da figura humana singular investida deste poder" (SAFFIOTI, 2008, p.153). Não se trata tampouco de uma ordem rígida que não permite trânsitos (melhoria nas condições de vida das mulheres, por exemplo) ou de uma ordem familiar (sabe-se que as mulheres já são responsáveis por mais de $40,5 \%$ das famílias, provendo seu sustento e sendo a pessoa de referência em seu grupo familiar) (IBGE, 2016)

Portanto, a ordem patriarcal não se refere a um contexto específico, a uma dimensão da sociedade, mas sim a um esquema que se reproduz por meio das relações e instituições 
sociais, como a família, a escola, a religião, e o Estado e, dessa forma, não é movido apenas pelos homens, mas por todo grupo social (SAFFIOTI, 2004).

O patriarcado organiza modos de vida que trazem, nos corpos, sua marca, naturaliza as relações sociais e garante à ideologia de gênero dominante um enraizamento difícil de ser desmontado. A existência de um patriarcado que opera por meio da necropolítica é uma chave analítica para entender a ocorrência dos feminicídios.

O reconhecimento da existência da necropolítica - política voltada para a exposição de determinados sujeitos à morte, em última instância definindo quem vai morrer e quem vai viver - tornou possível identificá-la nos modos de violência letal operadas pelo Estado (Achhile MBEMBE, 2003). De acordo com o autor:

As formas contemporâneas de subjugação da vida ao poder e à morte (necropolítica) reconfiguram profundamente as relações entre a resistência, o sacrifício e o terror [...] adiantei a noção de necropolítica e necropoder para dar conta das várias vias, pelas quais, em nosso mundo contemporâneo, as armas são utilizadas com vistas à máxima destruição de pessoas e a criação de mundos-mortos, novas e únicas formas de existência social, em que grandes populações são sujeitadas a condições de vida que conferem a elas o estatuto de mortos viventes (MBEMBE, 2003, p.24).

Neste sentido, o feminicídio é a expressão de uma necropolítica de gênero que pretende garantir a manutenção do status quo, obrigando as mulheres a seguirem as regras patriarcais estabelecidas (Montserrat SAGOT, 2013). "A necropolítica feminicida é a multiplicidade de mecanismos de soberania postos em operação por grupos diversos que exercitam um direito de vida e morte sobre corpos de mulher" (Ana María MARTíNEZ, 2013, p.11).

A necropolítica de gênero produz uma instrumentalização dos corpos das mulheres, constrói um regime de terror e decreta a pena de morte para algumas [...] representa a expressão última da masculinidade utilizada como poder, domínio e controle sobre a vida das mulheres (SAGOT, 2013, p.5).

A necropolítica de gênero, portanto, conforma um contexto sócio-político estrutural favorável à vulnerabilidade, que promove e tolera/mantém as desigualdades de gênero. Define quem importa e quem é descartável, e torna os corpos das mulheres utilizáveis. Torna possível por (entre outros elementos) uma descartabilidade biopolítica das mulheres, na medida em que há dispositivos sociais que contribuem para uma política voltada para a morte de mulheres.

\section{A visibilidade de um conjunto de mortes violentas de mulheres}

A vertente que nomeio "genérica" examina os feminicídios congregando e visibilizando um conjunto de mortes violentas de mulheres. "O conceito de feminicídio vai além de sua definição legal de assassinato, e inclui situações nas quais se aceita que as mulheres morram como resultado de atitudes misóginas ou práticas sociais" (Jill RADFORD, 2006, p.41). A ideia inicial, ao falar em feminicídio, seria envolver um sem número de possibilidades que levam à morte as mulheres, inclusive alguns suicídios que podem ser considerados suicídios feminicidas, se praticados num contexto que configurou situação de opressão sobre a vítima.

A compreensão da existência de uma violência feminicida permite ampliar a compreensão sobre as diversas e constantes situações de violência, nas quais milhões de mulheres são submetidas ao longo de suas vidas. Neste sentido, assim como afirma Russell (2006), muitas práticas misóginas e sexistas levam a uma situação de extrema violência, que podem culminar com a morte. O conceito de violência feminicida permite abarcar os 
casos de desaparecimento de mulheres, sustenta investigações sobre causas de suicídios, mas também incorpora as mortes maternas, as mortes de mulheres por aborto inseguro e todas as situações que indicam ação, ou omissão, pelo gênero da vítima. A concepção da existência de feminicídios neste contexto é ampla. Nesta vertente estão presentes todas as campanhas dos movimentos de mulheres e feministas, e os debates de Jill Radford e Diana Russell (2006) que abordam a violência letal da pornografia e os suicídios ocorridos em contextos feminicidas, assim como a discussão de Lagarde sobre a violência feminicida (Marcela LAGARDE, 2005; 2006).

No caso da mortalidade materna, por exemplo, as disparidades existentes entre os países, nas taxas de morte materna, revelam a possibilidade de evitar este tipo de morte, quando há resposta às demandas básicas das mulheres. "Hoje em dia, uma mulher corre mil vezes mais risco de morrer de complicações de gravidez se viver na África Subsaariana ou em certos países da Ásia, que se viver na Europa" (René FRYDMAN, 201 1, p.257).

Esta realidade é visível na América Latina, já que nenhum dos trinta e um países atingiu a meta de menos de 20 mortes por 100 mil habitantes até 2010 (PNUD, 2013). Ao considerar a questão racial, o fenômeno se agudiza. De acordo com o Ministério da Saúde brasileiro, entre 2000 e 2010 , morreram cerca de 600 mulheres brancas ao ano, e 1400 a 1600 mulheres negras, no mesmo período - a desigualdade é assoladora (Christine OKRENT; Sandrine TREINER, 2007).

Dentre as causas de morte materna está o aborto e, no Brasil, estima-se que a razão seja de 76 mortes para 100 mil mulheres em decorrência da prática do aborto inseguro. Para Radford (2006), ao impedir que as mulheres tenham o controle de seus corpos, o Estado as "empurra" para os abortos ilegais inseguros sendo responsável, portanto, por um sem número de feminicídios.

Considerar diversos contextos de morte como feminicídio tem um sentido político muito claro, contudo, amplia em demasia uma concepção conceitual, principalmente no contexto jurídico e contribui para sustentar mais dúvidas que esclarecimentos. Logo, tal concepção genérica ganha força na denúncia, no reconhecimento da base comum que sustenta a violência de gênero, praticada contra as mulheres.

\section{Nem todo homicídio de mulher é um feminicídio, todavia a maioria deles é}

Em geral, quando se fala de feminicídios, está se falando do assassinato de uma mulher - conforme apontado, este não é o único fenômeno compreendido no conceito, mas certamente é o principal. Sobre essa questão se concentra o maior número de publicações na América Latina. Até 2014 , se identificaram e analisaram 34 pesquisas realizadas em 15 países latino-americanos (GOMES, 2014).

Esta vertente é chamada de específica por que: 1) nomeia como feminicídio apenas o assassinato de uma mulher e não um conjunto de mortes violentas; 2) dentro dos assassinatos de mulheres, se reconhece que nem todos são feminicídios.

Um dos elementos que chama a atenção no caso dos homicídios de mulheres é o caráter desigual deste fenômeno, na medida em que as mulheres morrem em taxas desproporcionalmente superiores ao que matam (UNODC, 2011).

Enquanto os homens são assassinados com maior frequência que as mulheres, raras vezes se assassinam aos homens simplesmente porque são homens. Inclusive, em raríssimos casos em que as mulheres matam homens é pouco provável que matem porque a vítima é homem (RADFORD, 2006, p.48) 
Não é possível saber exatamente a incidência de autoria feminina nos crimes de homicídios, tampouco o respectivo sexo da vítima, mas pela população carcerária, é possível uma aproximação. Em 2014, somente 7\% dos estabelecimentos prisionais estavam destinados à população feminina no país (FÓRUM BRASILEIRO DE SEGURANÇA PÚBLICA, 2015), o que permite indicar a baixa incidência das mulheres na criminalidade e consequentemente, nas práticas violentas letais. Além disso, de acordo com o Departamento Penitenciário Nacional, (DEPEN) em 2014, apenas 2,3\% dos crimes cometidos pelas mulheres presas no sistema penitenciário eram homicídios (MINISTÉRIO DA JUSTIÇA, 2014)².

Além da desproporcionalidade entre matar e morrer, o que chama atenção nestes feminicídios é o seu contexto de produção, ou seja, as circunstâncias nas quais se produzem os crimes. Grande parte dos homicídios de mulheres ainda decorre de relações íntimas com homens com quem mantiveram alguma relação afetiva e/ou sexual - relações que muitas vezes a vítima tentava romper e/ou com vivência extremamente violenta (Suely Souza de ALMEIDA, 1998, GOMES, 2010). Dentre outros contextos de produção de feminicídio - da exploração sexual ou do tráfico de drogas, por exemplo - ainda que fique mais difícil a identificação da violência de gênero como propulsora do crime, em geral, a forma como é praticado e a pós-vitimização produzida, envolvendo tortura e violência sexual, mutilação nos órgãos genitais e destruição do que simboliza a feminilidade da vítima, são suficientes para identificar que houve sexismo, machismo e misoginia no caso (Maria das Dores Brito MOTA, 2010).

Neste sentido, construir descritores que sustentem critérios para compreender os feminicídios é tarefa fundamental na análise do fenômeno, considerando seus múltiplos contextos de ocorrência.

É evidente que somente uma caracterização precisa do modus operandi, presente em cada tipo particular de crime, e a elaboração de uma tipologia (o mais precisa possível) das diversas modalidades de assassinato de mulheres permitiria chegar à resolução dos casos, à identificação dos agressores e ao tão anelado fim da impunidade. Por isso esta diferenciação dos casos se torna um imperativo (Rita Laura SEGATO, 2008, p.44).

Existem distintas maneiras para analisar ${ }^{3}$ os feminicídios, definidos a partir dos assassinatos de mulheres. Uma classificação inicial, bastante utilizada, (Russell, 2006; Carcedo, 2000) indicava apenas três tipos de feminicídio: íntimo, não íntimo e por conexão, quando a vítima estava na "linha de fogo" (quando uma mulher é assassinada por vingança de uma discussão entre homens, por exemplo). Posteriormente Carcedo e Sagot (2010) construíram a noção de "cenários de feminicídio":

Definimos o conceito cenário de femicidio como: os contextos socioeconómicos, políticos e culturais nos que se produzem ou propiciam relações de poder entre homens e mulheres particularmente desiguais e que geram dinâmicas de controle, violência contra as mulheres e femicídios que adotam ou incluem características próprias (CARCEDO, 2010, p.15).

\footnotetext{
${ }^{2}$ Cabe ressaltar que o perfil da população, no referido informe, não indica a diferença revelando o descaso e a invisibilidade da população feminina carcerária no Brasil. Vários estudos denunciam essa situação. É importante refletir sobre a problemática da criminalidade feminina quando se observa que apenas $25 \%$ dos homens presos cometeram crimes relacionados às drogas contra $63 \%$ do total desses crimes cometidos pelas mulheres (MINISTERIO DE JUSTIÇA, 2014).

${ }^{3}$ Para mais informações sobre os casos de feminicídios e a pedagogia da crueldade realizada no corpo das mulheres, ver pesquisas para o caso brasileiro realizadas no Rio de Janeiro (ALMEIDA, 1998), São Paulo (Eva BLAY, 2008), Ceará, (Maria Helena de Paula FROTA,2012), Cuiabá (GOMES, 2010; 2013), Porto Alegre ( Stela MENEGHEL , 2013), e em cinco Estados do país - Bahia, Mato Grosso, Minas Gerais, Pará e Paraná (Marta Rodrigues de Assis MACHADO, 2014).
} 
Julia Monárrez (2000, 2002, 2010), a partir de suas pesquisas sobre os crimes de Ciudad Juárez, no México, construiu uma tipologia para os feminicídios, tentando indicar os distintos contextos no qual as mulheres são assassinadas.

Tabela 1. Classificação de Feminicídios na América Latina

\begin{tabular}{|c|c|c|}
\hline $\begin{array}{l}\text { Tipologgia de Feminicidios } \\
\text { (Monărrez et al, 2010) }\end{array}$ & $\begin{array}{l}\text { Trés tipos de } \\
\text { Feminicidio } \\
\text { (Carcedo, } 2000 \text { e } \\
\text { outros) }\end{array}$ & $\begin{array}{c}\text { Cenários de } \\
\text { Feminicidios } \\
\text { (Carcedo e Sagot, 2010) }\end{array}$ \\
\hline $\begin{array}{l}\text { Feminicidio intimo } \\
\text { (compreende alèm da intimidade, } \\
\text { a familia e o assassinato contra } \\
\text { crianças) }\end{array}$ & Intimo & Familaa \\
\hline $\begin{array}{l}\text { Feminicidio por ocupaçōes } \\
\text { estigmatizadas } \\
\text { (garçonetes e dançarinas que } \\
\text { trabalham em casas de show e } \\
\text { prostitutas) }\end{array}$ & Nào intimo & $\begin{array}{l}\text { Relaçòes afetivas } \\
\text { (namorados, noivos, } \\
\text { companheiros, cónjuges, } \\
\text { amantes - atual ou ex) }\end{array}$ \\
\hline $\begin{array}{c}\text { Feminicidio sexual sistermico } \\
\text { organizado }\end{array}$ & Por conexho & Ataque sexual \\
\hline \multirow[t]{7}{*}{$\begin{array}{l}\text { Feminicidio sexual sistêmico } \\
\text { desorganizado }\end{array}$} & & Comércio sexual \\
\hline & 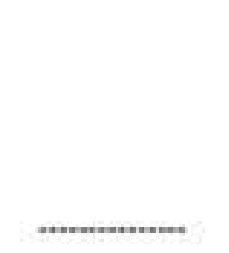 & $\begin{array}{l}\text { Trifico de mulheres para } \\
\text { todo tipo de exploraçđ̄o } \\
\text { Mrifias e redes } \\
\text { criminosas nacionais e } \\
\text { internacionais }\end{array}$ \\
\hline & & Gangues \\
\hline & & Territónio de vingança \\
\hline & & Misoginia \\
\hline & & Cenärios entrelaçados \\
\hline & & $\begin{array}{l}\text { Cenários evasivos - } \\
\text { Suspeita de feminicidio }\end{array}$ \\
\hline
\end{tabular}

Fonte: Elaboração própria (GOMES, 2014).

8 Revista Estudos Feministas, Florianópolis, 26(2): e39651 
É evidente que sempre há um entrelaçamento de elementos na ocorrência dos feminicídios. A conceituação de cenários e a tipologia são aproximações necessárias e bastante elucidativas, construídas a partir da experiência feminista de pesquisa e análise dos feminicídios na América Latina. A complexidade da realidade deve envolver uma ampla visão, cujos conceitos possibilitem sua compreensão.

A partir do exame de pesquisas e legislações latino-americanas, foi possível identificar não haver dúvidas que se constituem em feminicídios os assassinatos nos casos em que:

- Havia relação familiar, afetiva e/ou de intimidade entre as partes (atual ou pregressa).

- Havia relações de poder que implicavam confiança, autoridade e subordinação (chefia, relação laboral e docente), atual ou pregressa.

- Ocorreu violência sexual e/ou estupro.

- A vítima era trabalhadora do sexo.

- Houve violência pregressa (inclusive ameaças) por parte do autor do crime, denunciadas formalmente ou não.

- Foram cometidas ações que aumentaram o sofrimento da vítima e/ou revelaram sinais de misoginia e ódio contra a vítima mulher: numerosos golpes, utilização de vários tipos de armas, decapitações, mutilações e outros. Qualquer indicação de que houve mutilação e tortura.

- O crime ocorreu no marco de rituais de grupos, gangues ou com finalidade religiosa.

- O corpo foi exibido em lugar público e/ou construção de cena humilhante, moralmente, para a vítima, como deixar preservativos perto do corpo, deixá-la nua ou seminua, ou qualquer tipo de cenário construído intencionalmente.

- O crime foi precedido de sequestro.

- O crime foi cometido na frente de filhos e filhas da vítima.

Os intervenientes elencados indicam evidente desigualdade de gênero marcada pela noção de poder, dominação-exploração e posse, reconhecidas pelo autor do crime sobre a vítima. Há outras situações mais específicas, que podem deixar dúvidas ou trazer à tona novas realidades, por isto, outros descritores podem ser construídos com base em cada contexto, sabendo que são comuns múltiplas características mesclarem-se na ocorrência do fenômeno. A realização de pesquisas possibilitará o aparecimento de novos elementos.

No caso dos feminicídios reconhecidos a partir do assassinato de mulheres é importante observar diversos indicadores, tais como a relação com a violência urbana, com as políticas sociais vigentes e, especialmente, a questão do tráfico de drogas, do turismo sexual e do tráfico de pessoas. Todos esses elementos complexificam a ocorrência do fenômeno.

\section{Respostas penais adequadas aos assassinatos de mulheres: - debate sobre a judicialização dos feminicídios}

Feminicídio, semanticamente, remete à palavra homicídio, o que permite rapidamente uma dupla associação: 1) O conceito abarca apenas os assassinatos de mulheres. 2) O debate sobre feminicídios implica demandar um novo tipo penal, ou alguma nova maneira de tratamento penal. Contudo, estas compreensões são limitadas, pois a judicialização é uma das vertentes do debate sobre os feminicídios, que expressa um tipo de resposta possível no enfrentamento ao fenômeno, sem significar a totalidade desta discussão. Muito antes dos Estados mobilizarem-se para responder às demandas pela criação de um tipo penal, os movimentos de mulheres e feministas já problematizavam a 
existência do feminicídio, sem necessariamente ser favorável à exigência de uma resposta mais específica por parte do direito penal para o fenômeno.

Autoras como Rita Laura Segato $(2006 ; 2008 ; 2011$; 2013), Patsíli Toledo $(2008,2009)$ e Lucía Melgar (2011), além de posicionar-se favorável ou contrariamente à criação de tipos penais, chamam a atenção para esse amplo debate e no que implica socialmente reconhecer, juridicamente, o feminicídio. A aposta das autoras está centrada na necessidade do enfrentamento de uma sociedade patriarcal, que utiliza e descarta o corpo das mulheres.

Nos anos 2000, considerando a incidência e a gravidade dos feminicídios, o alto grau de impunidade destes crimes e a pressão social dos movimentos feministas e de mulheres, alguns Estados passaram a responder penalmente ao problema (Ana Isabel Vilchez GARITA, 2013). Até 2015, foram nove os países a realizar alguma modificação em seu Código Penal, para enquadrar o feminicídio: Costa Rica (2007), Guatemala (2008), Chile (2010), Peru (201 1), El Salvador (2012), México (2012) e Nicarágua (2012). Brasil (2015) e Colômbia (2015) (GARITA, 2013; GOMES, 2015).

Nesta última seção, o que se pretende é abordar a relação entre o feminicídio e a legislação penal, evidenciando que não é o mesmo reconhecer e denunciá-lo como fenômeno social, que legislar penalmente sobre ele $^{4}$.

Enfatiza-se aqui, que a vertente denominada judicializadora do feminicídio, trata de uma resposta, ou uma modalidade de enfrentamento ao problema, muito mais que uma discussão em si, sobre ele. Essa vertente reconhece como feminicídio alguns assassinatos de mulheres, a partir de alguns critérios, e cria uma legislação, que pode ser uma nova lei, ou uma alteração no código penal, para responder ao fenômeno.

A ausência do reconhecimento de que esta é apenas uma abordagem sobre o feminicídio, reduz um fenômeno social a um debate penal, sendo que é muito importante entender que o feminicídio existe como problema social, como expressão letal da violência de gênero e pode ou não, ser reconhecido penalmente. Assim, ao construir uma relação direta entre o feminicídio e a reivindicação de um novo tipo penal - reduzindo-o a um enquadramento jurídico e desconsiderando sua existência com múltiplas determinações verifica-se grande equívoco, porque o que tal vertente pretende é um debate sobre a judicialização específica dos assassinatos de mulheres em razão do gênero.

Cabe ressaltar que não é corrente um debate contrário à judicialização dos homicídios - há consenso sobre a necessidade de um tipo penal, que responda aos crimes contra a vida - no caso, o tratamento penal dado aos homicídios. Portanto, o eixo das argumentações, repletas de disputas e tensões, está na discussão sobre a pertinência de um tratamento penal adequado e específico para os feminicídios, que não encontram respostas no enquadramento do crime de homicídio, pela complexidade de elementos que o compõe no campo da violência de gênero contra as mulheres.

São numerosas as críticas e forte a resistência para uma possível resposta penal aos crimes de feminicídio como tal. Muitas destas críticas consistem em argumentos razoáveis, principalmente porque reconhece os limites e o lugar das leis penais no sistema capitalista, contudo, a maioria dos argumentos carece do reconhecimento da gravidade, da brutalidade e da base estruturalmente desigual na qual ocorrem as violências praticadas contra as mulheres.

São cinco os principais argumentos que fundamentam uma posição contrária a esta dinâmica de "ingresso" penal, específico do sistema de justiça de cada país. 1) É preciso manter o princípio do direito penal mínimo; 2) o feminicídio já está contemplado no

${ }^{4}$ Para maior discussão sobre o tema, incluindo o debate sobre a pertinência ou não de um tratamento penal específico para o feminicídio, ver Gomes $(2014,2015)$. 
homicídio qualificado; 3) os problemas de técnica legislativa podem tornar inconstitucional a nova lei; 4) não há redução nas taxas do fenômeno, tampouco se resolve o problema da impunidade com a criação de um tipo penal, ou com o aumento de penas; 5) o sistema penal não pode ser demandado por um sentido simbólico e sim por sua eficácia reconhecidamente limitada (CLADEM, 2011).

Ainda que todos estes argumentos tenham fundamento jurídico, e também resposta (GOMES, 2015), o que se espera neste texto é problematizar quais seriam os significados de garantir ou rechaçar uma lei penal, que sanciona a violência de gênero letal contra as mulheres.

Existe um conteúdo simbólico, que não pode ser menosprezado na tipificação do feminicídio, anunciando uma morte não ocasional, além de reconhecidamente, premeditada (GOMES, 2010). O reconhecimento penal de maneira específica e adequada do feminicídio é uma tentativa de nomear um conjunto complexo, que implica a letalidade e a barbárie da violência dirigida às mulheres, "não é nada comparado com a violência de gênero que a palavra tenta descrever (Lourdes ENRIQUEZ, 2010, p.72), pois não há palavra que expresse o horror que impregna a prática do feminicídio, desde as vivências anteriores da violência, como as posteriores, da mensagem que se queria anunciar.

Para Enriquez (2010, p.74), tipificar "confronta a universalidade da lei com a singularidade do que ela nomeia" e é por isso que, mais do que crer na eficácia ou na efetividade do direito penal, recorrer a ele representa posicionar-se politicamente em meio a disputas de poder. $O$ poder de nomear, o poder de dizer o que é importante definir no imaginário social como grave, como crime ou não. Por isso, Segato (2011) é direta ao anunciar "o direito a nomear o sofrimento no direito" para fomentar a discussão do seu significado social e as disputas em questão.

Ademais, se deve reconhecer o campo jurídico em especial, sem uma perspectiva de neutralidade, mas como um campo discursivo no qual atores e papéis estão em disputa (SEGATO, 2011 ; CORRÊA, 1983). O campo jurídico está repleto de hierarquias e desigualdades cujas características são inerentes a um sistema que o sustenta, qual seja, o de dominaçãoexploração contra as mulheres, o de classe, raça e gênero, que mantém o capitalismo e o patriarcado. E é no interior deste campo, que as disputas são travadas. Nessa perspectiva, se confirma a ideia de que a luta pela formulação de leis é também a "luta pela nominação, pela consagração jurídica dos nomes do sofrimento humano [...] e a luta por publicizar e por colocar em uso, na boca das pessoas, as palavras da lei" (SEGATO, 201 1, p.249).

O discurso jurídico confere existência às comunidades e suas respectivas identidades e legitima ou não determinadas demandas, dando sentido (ou não) a elas. A lei, nesse aspecto, tem uma eficácia normativa no sentido de interpelar - e até mesmo controlar - a concepção das pessoas sobre o que é decente e indecente, bom e mau. "É a luta pelo acesso, e a inscrição na narrativa jurídica, de dois sujeitos coletivos pugnando por obter reconhecimento no contexto da nação" (SEGATO, 2011, p.251).

A eficácia nominativa da lei, portanto, consiste na legitimidade dada a alguns sujeitos, cujo "discurso é válido e o sofrimento social que nomina está oficialmente reconhecido" (SEGATO, 2011 , p.253).

Na criação de uma resposta penal ao feminicídio o debate se amplia porque o que está em questão é o reconhecimento da desigualdade de gênero e do conjunto de violências sofridas pelas mulheres ao longo da vida, que passa a ser nomeado penalmente quando se reconhece a letalidade deste contexto.

Em alguns argumentos contrários à judicialização da violência de gênero em geral, encontram-se argumentos claramente patriarcais, na medida em que impedem a 
identificação da dor, do sofrimento, da brutalidade da morte implicada nos feminicídios e o significado disto no contexto de relações sociais extremamente desiguais.

Sendo assim, se conhece a complexidade do debate sobre a criação de mais uma lei penal e não há uma crença cega no Estado e em suas instituições, mas a ampliação do leque de compreensões, tendo em vista caminhos possíveis de serem trilhados. Não obstante esses argumentos, há décadas Segato chama a atenção para as possibilidades de transformação da realidade social que não emergem nem do Estado, tampouco do direito penal. O conceito que desenvolve, de femigenocídio, amplia o argumento no caminho das cortes internacionais e de um debate muito mais amplo com as denúncias dos movimentos sociais (SEGATO, 2013).

Melgar (2011) adverte para o risco de que os feminicídios, ao serem reconhecidos penalmente, significarem somente a expressão de um fato terrível, dita numa palavra desgastada, que aparece no código penal e na imprensa como um assassinato a mais. Hoje, dez anos depois das primeiras legislações de feminicídios sancionadas na América Latina, caberia a avaliação e a reflexão sobre os possíveis avanços alcançados. De acordo com Segato (2017), "nunca houve mais leis nem mais instituições como agora e estamos cada vez pior" (sem página). Logo, as legislações penais são apenas uma das numerosas possibilidades no caminho que constrói a prevenção e a erradicação dos feminicídios.

\section{Conclusão}

O feminicídio existe na realidade - é a expressão letal e representa a dimensão mais brutal da violência de gênero praticada contra as mulheres. A necessidade de tal afirmação revela a dificuldade de visibilizar e tornar relevante as experiências das mulheres, inclusive aquelas que passam pela violência e pela dor.

O feminicídio é toda morte violenta de uma mulher, morte esta evitável, mas plenamente possível, num contexto social onde está presente o esquema de dominaçãoexploração, sustentado por uma sociedade patriarcal, racista e capitalista que atinge a mulheres e homens de modo contraditório. Nesse contexto, as relações sociais estão marcadas por profundas desigualdades, que extrapolam a condição de gênero, mesclando-se com a condição de classe social, de raça/etnia e se estendem às identidades sexuais, ao pertencimento geracional, às questões religiosas e às vivências sócio-territoriais.

Se os homicídios de mulheres marcados pela violência de gênero é motivo de denúncia pelos movimentos feministas desde os anos 70 , o reconhecimento dos feminicídios ocorreu ainda mais recentemente, fortemente marcado pelas singularidades territoriais e foi protagonizado, principalmente, pelas mães e familiares das vítimas. A avalanche de denúncias, de contrarrespostas estatais que insistiam em privatizar e despolitizar os casos e o conjunto de pesquisas realizadas (mas publicizadas de maneira isolada na América Latina) possibilitou uma imensidão de críticas e questionamentos acerca da existência dos feminicídios.

A pesquisa realizada a partir da análise da produção epistemológica feminista latino-americana, ainda que limitada, apontou que é preciso aclarar o que se quer dizer quando se fala em feminicídio.

Chamar de feminicídio um fato que é produto de um conjunto de violências pregressas, e que compreende: letalidade, desigualdade de condições, não acidentalidade, intencionalidade em função do gênero do sujeito, e em muitos casos, crueldade e brutalidade, é uma maneira de publicizar, politizar e colocar na ordem do dia o problema da morte violenta de mulheres que constitui um grave fenômeno social, porque coloca em risco mais da metade da população mundial. Neste sentido, dizer feminicídio 
não é simplesmente substituir um vocábulo por outro (mortes violentas ou assassinato), mas reconhecer um fenômeno e expressar o conjunto de elementos que o conformam e, portanto, revelar uma concepção teórica acerca da realidade.

Há que se insistir na necessidade de reconhecimento das três vertentes do debate, presentes na literatura existente, que discorre sobre os feminicídios. Falar das mortes violentas de mulheres em sua totalidade não é o mesmo que analisar os assassinatos de mulheres, bem como é muito diferente da reivindicação de um tratamento penal adequado. Cada uma dessas ênfases revela uma compreensão do fenômeno e um objetivo em questão, seja denunciar um conjunto de violações e violências sistemáticas, conhecer as especificidades das mortes por assassinato, ou buscar justiça, punição e reconhecimento da gravidade dos crimes. Conhecer e enunciar a perspectiva de onde se fala é fundamental para tornar o debate e o diálogo mais fluídos e compreensíveis em meio a um mosaico de concepções teórico-metodológicas que visa enfrentar o problema.

Tamanha pluralidade de maneira alguma deve enfraquecer o potencial discursivo e analítico do feminicídio. Ao contrário, deve evidenciar os múltiplos elementos que constituem o fenômeno da morte violenta de mulheres, tarefa que constitui verdadeiro campo minado a ser trilhado no reconhecimento da violência de gênero como uma morte (mal) anunciada.

\section{Referências}

ALMEIDA, Suely Souza de. Femicídio: Algemas invisíveis do público-privado. Rio de Janeiro: Revinter, 1998

BANDEIRA, Lourdes. "A Contribuição da crítica feminista à ciência". In: Revista Estudos Feministas, Florianópolis, v. 16, n. 1, p. 207-228, jan-abril 2008.

BLAY, Eva. Assassinato de Mulheres e Direitos Humanos. São Paulo: 34, 2008.

CLADEM. Comitê da América Latina e Caribe para Defesa dos Direitos da Mulher. Contribuciones al debate sobre la tipificación penal del femicidio/feminicidio. Lima, Peru, 2011

CARCEDO, Ana; SAGOT, Montserrat. Femicidio en Costa Rica: 1990-1999. Colección Teórica 1. Instituto nacional de las mujeres: San José, Costa Rica, 2000.

CARCEDO, Ana; SAGOT, Montserrat. No olvidamos y ni aceptamos: femicidio en Centroamérica (2000-2006). 1 ed. Asociación Centro Feminista de Información y Acción (CEFEMINA): San José, Costa Rica, 2010.

CORRÊA, Mariza. Os crimes da paixão. Coleção Tudo é história, v. 33, São Paulo: Editora Brasiliense, 1981.

CORRÊA, Mariza. Morte em família. Rio de Janeiro: Graal, 1983.

DEBERT, Guita Guin; ARDAILLON, Daniele. Quando a vítima é mulher: análise de julgamentos de crimes de estupro, espancamento e homicídio. Conselho Nacional dos Direitos da Mulher: Brasília, 1987.

ENRIQUEZ, Lourdes. "Eficacia performativa del vocablo feminicídio y legislación penal como estrategia de resistencia". In: MARTíNEZ, Ana María de la Escalera (org). Feminicídio actas de denuncia y controversia. Cidade do México: PUEG/UNAM, 2010.

FARGANIS, Sondra. "O feminismo e a reconstrução da Ciência Social". In: JAGGAR, Alison; BORDO, Susan R. (Orgs.). Gênero, corpo e conhecimento. Rio de Janeiro: Rosa dos Tempos, 1997.

FÓRUM BRASILEIRO DE SEGURANÇA PÚBLICA. Anuário do Fórum Brasileiro de Segurança Pública. Fórum Brasileiro de Segurança Pública: São Paulo, ano 9, 2015.

FROTA, Maria Helena de Paula et al. Assassinato de mulheres no Ceará. Série: Informativos do Observem. Fortaleza: EDUECE, 2012. 
FRYDMAN, René. "A mortalidade materna". In: OCKRENT, Christine; TREINER, Sandrine (Orgs). O livro negro da condição das mulheres. Rio de Janeiro: Difel, 2011.

GARGALLO, Francesca. Ideas Feministas Latinoamericanas. $2^{\circ}$ edição ampliada. Cidade do México: Edição Digital. 2006. Disponível em: http://pmayobre.webs.uvigo.es/descargar_ libros/las\%2Oideas\%2Ofeministas\%2Olatinoamericanas.pdf. Acesso em 02/04/2014.

GARITA, Ana Isabel Vílchez. La regulación del delito de femicidio/feminicídio en América Latina. Campaña del Secretario General de las Naciones Unidas ÚNETE para poner fin a la violencia contra las mujeres. Panamá, 2013.

GOMES, Izabel Solyszko. "Femicidio: A (mal) anunciada morte de mulheres". In: Revista de Políticas Públicas, Maranhão, v. 14, n1, p. 17-27, jan./jun., 2010.

"Femicidio y feminicídios: avances para nombrar la expresión letal de la violencia de género contra las mujeres". In: Revista Géneros. Universidad de Colima: México, n. 13, p. 23-41, mar./ago., 2013.

. Morreram porque mataram: tensões e paradoxos na compreensão do feminicídio. 2014. Tese (Doutorado em Serviço Social). Programa de Pós-Graduação em Serviço Social, Universidade Federal do Rio de Janeiro, Rio de Janeiro, RJ, Brasil, 2014.

"Feminicídios e possíveis respostas penais: dialogando com o feminismo e o direito penal". In: Revista Gênero e Direito. João Pessoa, v. 4, n. 1, p. 188-218, 2015.

JIMENO, Myriam. Crimen pasional: con el corazón en tinieblas. Série Antropologia, UNB: Brasília, 2002.

LAGARDE, Marcela. "Del femicidio al feminicidio". In: Revista Desde el jardin de Freud, v. 6, p. 216-225. Universidad Nacional de Colombia: Bogotá, 2006.

"El feminicídio, delito contra la humanidad". In: Feminicídio, Justicia y Derecho. Comisión Especial para Conocer y dar Seguimiento a las Investigaciones relacionadas con los Feminicídios en la Republica Mexicana, México, 2005.

MACHADO, Marta Rodrigues de Assis. Estudo sobre assassinato de mulheres por razões de gênero: feminicídio. FGV Direito. São Paulo, 2014.

MARTÍNEZ, Ana María de la Escalera. (Coord). Feminicídio: actas de denuncia y controversia. México: PUEG/UNAM, 2010.

MARTíNEZ, Ana María de la Escalera; LINDIG, Erika Cisneros (orgs). Alteridad y exclusiones: vocabulario para el debate social y político. Cidade do México, 2013. (mimeo).

MBEMBE. Achhile. "Necropolitics". Public Culture, v. 1, p. 11-40, dez./mar. Nova York: 15, 2003.

MELGAR, Lucia. "Ni un poquito de justicia? El feminicídio en Ciudad Juarez y la sentencia del Campo Algodonero". In: ¿Y usted cree tener derechos? Acceso de las mujeres mexicanas a la justicia. Cidade do México: PUEG/UNAM, 2011. p.83-112.

MENEGHEL, Stela et al. "Femicidios: narrativas de crimes de gênero". In: Interface, Botucatu, v. 17, n. 46, p. 523-33, jul./set. 2013.

MILLET, Kate. Política Sexual. Edições Dom Quixote: Lisboa, 1970.

MINISTÉRIO DA JUSTIÇA. Levantamento Nacional de Informações Penitenciárias. Brasília, DF, 2014.

MINISTÉRIO DA SAÚDE. 20 anos de pesquisas sobre aborto no Brasil. Ministério da Saúde: Brasília, 2009.

MINISTÉRIO DA SAÚDE. Mortalidade materna no Brasil: principais causas de morte e tendências temporais no período de 1990 a 2010. 2013. Disponível em: http:// portalsaude.saude.gov.br/portalsaude/arquivos/pdf/2013/Fev/21/ saudebrasil2011_parte2_cap14.pdf. Acesso em: 11/12/2013.

MONÁRREZ, Julia Estela Fragoso. "La cultura del feminicídio en Ciudad Juarez - 19932001". In: Revista Frontera Norte, v. 12, n. 23, p. 87-117, enero-julio, El Colegio de la Frontera Norte: Mexico, 2000.

14 Revista Estudos Feministas, Florianópolis, 26(2): e39651 
"Feminicídio sexual serial en Ciudad Juarez: 1993 - 2001". In: Revista Debate Feminista, "Violencias", Ciudad de México, Ano 13, v. 25, p. 279-305, abril, 2002.

MONÁRREZ, Julia Estela Fragoso et al. Violencia contra las mujeres e inseguridad ciudadana en Ciudad Juárez. Editora Miguel Ángel Porrúa: México, 2010.

MOTA, Maria das Dores Brito. Feminicídio: uma proposta de tipologia. In: Blog Geledés, 2010. Disponível em: https://www.geledes.org.br/feminicidio-uma-proposta-de-tipologia. Acesso em 02/04/2013.

PASINATO, Wania. “'Femicidios' e a morte de mulheres no Brasil”. In: Cadernos Pagu. Campinas, n. 37. p. 219-246, jul.-dez. 2011.

OKRENT, Christine; TREINER, Sandrine. O livro negro da condição das mulheres. Algés: Difel, 2007.

PNUD, Programa das Nações Unidas para o Desenvolvimento. Relatório do Desenvolvimento Humano 2013: a ascensão do Sul - Progresso Humano num mundo diversificado. ONU: Nova York, 2013.

RADFORD, Jill. "Introducción”. In: RUSSEL, Diana. RADFORD, Jill (Orgs). Feminicídio, La política del asesinato de las mujeres. CEIICH/UNAM: Cidade do México, 2006.

RUSSEL, Diana. RADFORD, Jill. Feminicídio. La política del asesinato de las mujeres. CEIICH/ UNAM: Cidade do México, 2006.

SAFFIOTI, Helleieth. Gênero, patriarcado e violência. São Paulo: Fundação Perseu Abramo, 2004.

"A ontogênese do gênero". In: A construção dos corpos feministas. Florianópolis: Mulheres, 2008.

SAGOT, Montserrat. "El femicidio como necropolítica en Centroamérica". In: Labrys Estudos Feministas, Brasília, Montreal, Paris, n. 24, jul.-dez. 2013.

SEGATO, Rita Laura. "¿Que és un feminicídio? Notas para un debate emergente". In: Fronteras, violencia, justicia: nuevos discursos. PUEG/UNIFEM: Cidade do México, 2008.

"Femigenocidio y feminicidio: una propuesta de tipificación". In: Labrys Estudos Feministas, Brasília, Montreal, Paris, n. 24, jul.-dez. 2013. Edição digital. Disponível em: https://www.labrys.net.br/labrys24/feminicide/rita.htm. Acesso em 1 1/04/2014.

La escritura en el cuerpo de las mujeres asesinadas en Ciudad Juarez: Territorio, soberania y crímenes de segundo estado. Cidade do México: Universidad del Claustro de Sor Juana, 2006.

"Femi-geno-cidio como crimen en el fuero internacional de los Derechos Humanos: el derecho a nombrar el sufrimiento en el derecho". In: FREGOSO, Rosa Linda; BEJARANO, Cynthia (Orgs). Feminicídio en América Latina. Diversidad Feminista. CEIICH/UNAM: Cidade do México, 2011.

TOLEDO, Patsíli Vázquez. ¿Tipificar el femicidio? In: Anuario de Derechos Humanos 2008, n.4. Centro de Derechos Humanos, Universidad de Chile, Santiago, Chile, edição anual, p. 213-219, 2008.

Femicidio. Consultoría para la Oficina en México del Alto Comisionado de las Naciones Unidas para los Derechos Humanos. Oficina del Alto Comisionado para los Derechos Humanos. México, 2009.

UNODC - United Nations Office on Drugs and Crime. Global study on homicide L2011. Viena, Austria, 2011.

[Recebido em 09/07/2015, reapresentado em 09/06/2017 e aprovado em 25/08/2017] 


\section{Femicides: a Long Debate}

Abstract: The problem of women's violent deaths was denounced by feminist movements for over thirty years. Therefore, it is a longstanding knowledge that gender violence has a lethal expression over women. However, the acknowledgment of these deaths as "feminicide" is a more recent process. The aim of the present article is to present an outlook of the Latin American feminist epistemological production which recognizes three emphasis in the analysis, understanding and response to those femicides. The first emphasis is described as a set of several violent deaths due to gender. The second is the murders whose characteristics conforms a femicide and finally the third emphasis is the revindication for a specific criminal response to the phenomenon. The debate is longlasting, but it is extremely relevant due to women's violent death rates.

Keywords: Feminicide; Gender violence; Feminist epistemology

Izabel Solyszko Gomes (iza.ufrj@gmail.com) é docente e pesquisadora na Universidad Externado de Colombia. Integrante do grupo de pesquisa Estudios de Familia da Facultad de Ciencias Sociales dessa universidade. Doutora em Serviço Social pela Universidade Federal do Rio de Janeiro e assistente Social. Pesquisadora nos temas de gênero, violência de gênero com especial atenção aos feminicídios, justiça e direitos humanos. Desenvolve pesquisa sobre as estratégias de resistência realizadas por grupos de mulheres no contexto do conflito armado colombiano. 